\title{
Composition-function relations of cartilaginous tissues engineered from chondrocytes and mesenchymal stem cells isolated from bone marrow and infrapatellar fat pad
} \author{
Ireland. \\ Running title: \\ Engineered cartilage from different MSC sources \\ * Address for correspondence: \\ D. J. Kelly \\ Trinity Centre for Bioengineering \\ School of Engineering \\ Trinity College Dublin \\ Dublin 2 \\ Ireland \\ Telephone: +353-1-896-3947 \\ Fax: +353-1-679-5554 \\ E-mail address: kellyd9@tcd.ie
}

T. Vinardell, C.T. Buckley, S. D. Thorpe, and D. J. Kelly*.

Trinity Centre for Bioengineering, School of Engineering, Trinity College Dublin,

Key Words: Infrapatellar fat pad; Cartilage; TGF- $\beta 3$; Mesenchymal stem cells; Chondrocytes; Hydrogel. 


\begin{abstract}
The objective of this study was to determine the functional properties of cartilaginous tissues generated by porcine MSCs isolated from different tissue sources, and to compare these properties to those derived from chondrocytes (CC). MSCs were isolated from bone marrow (BM) and infrapatellar fat pad (FP), while $\mathrm{CC}$ were harvested from the articular surface of the femoro-patellar joint. Culture-expanded CC and MSCs were encapsulated in agarose hydrogels and cultured in the presence of TGF- $\beta 3$. Samples were analysed biomechanically, biochemically and histologically at day 0 , day 21 and day 42. After 42 days in free swelling culture, mean GAG content was $1.50 \% \mathrm{w} / \mathrm{w}$ in $\mathrm{CC}$ seeded constructs, compared to $0.95 \% \mathrm{w} / \mathrm{w}$ in FP and $0.43 \%$ w/w in BM seeded constructs. Total collagen accumulation was highest in FP constructs. DNA content increased with time for all the groups. The mechanical functionality of cartilaginous tissues engineered using CCs was superior to that generated from either source of MSCs. Differences were also observed in the spatial distribution of matrix components in tissues engineered using CC and MSCs, which appears to have a strong influence on the apparent mechanical properties of the constructs. Therefore while functional cartilaginous tissues can be engineered using MSCs isolated from different sources, the spatial composition of these tissues is unlike that generated using chondrocytes, suggesting that MSCs and chondrocytes respond differently to the regulatory factors present within developing cartilaginous constructs.
\end{abstract}




\section{Introduction}

Due to its limited capacity for regeneration and self repair, as well as a paucity of therapeutic options, degeneration of articular cartilage can have severe consequences (Pelttari et al., 2008). Clinical procedures for cartilage defect repair such as subchondral abrasion arthroplasty, microfracture or autologous chondrocyte implantation often result in only a temporary partial repair, producing a biomechanically inferior tissue that can ultimately degenerate leading to osteoarthritis (Schumann et al., 2006). Engineering functional cartilage tissue using mesenchymal stem cells (MSCs) seeded into scaffolds or hydrogels represents a promising alternative treatment for articular cartilage defects. Many adult tissues maintain populations of MSCs that are not terminally differentiated and which could potentially be used for tissue regeneration following trauma, disease or aging (Pittenger et al., 1999; Fuchs and Segre 2000; Hadjantonakis and Papaioannou 2001; Wickham et al., 2003). Such cells possess the ability to proliferate extensively ex vivo while maintaining their differentiation capabilities (Caplan 1991; Pittenger et al., 1999).

Bone marrow (BM) derived MSCs have been studied extensively in vitro for their capacity to differentiate and synthesize markers associated with adipocytes, chondrocytes (CC) and osteoblasts (Maniatopoulos et al., 1988; Caplan 1991; Johnstone et al., 1998; Pittenger et al., 1999), and for their ability to generate a mechanically functional cartilaginous tissue (Mauck et al., 2006; Mauck et al., 2007; Thorpe et al., 2008; Thorpe et al., 2008; Erickson et al., 2009; Huang et al., 2009). However traditional bone marrow procurement procedures may be painful, time consuming, expensive and risk cell contamination and loss (Pelttari et al., 2008; Khan et al., 2009). An ideal source of autologous cells would be both easy to obtain and 
would result in minimal patient discomfort during harvesting (Zuk et al., 2001). Recent studies have shown that MSCs isolated from other connective tissues such as fat pad (FP), synovial membrane and subcutaneous fat may possess significant plasticity in their multi-lineage capabilities (De Bari et al., 2001; Zuk et al., 2001; Zuk et al., 2002; Dragoo et al., 2003; Wickham et al., 2003; Huang et al., 2005; English et al., 2007; Pei et al., 2008). These tissues represent attractive cell sources for tissue engineering because they are generally accessible with minimal donor site morbidity.

Comparisons of the chondrogenic potential of different sources of MSCs (synovium, bone marrow, subcutaneous fat and muscle) in a pellet culture system suggest that synovial membrane derived MSCs possess a superior chondrogenic capability to other sources (Koga et al., 2008). It has also been reported that human osteoarthritic fat pad (FP) tissue contains highly clonogenic and multipotent MSCs with stable chondrogenic potential in vitro (English et al., 2007), which express markers common with other sources of MSCs (Khan et al., 2008). We have recently demonstrated that functional cartilaginous tissue can be engineered using infrapatellar FP derived MSCs embedded in agarose hydrogel (Buckley et al., 2009). While it has been demonstrated that cartilaginous tissues engineered using BM derived MSCs embedded in agarose hydrogel possess inferior mechanical properties to those engineered using CC (Mauck et al., 2007; Erickson et al., 2009), it is unclear if this finding extends to MSCs isolated from sources other than the bone marrow.

The objective of this study is to compare the biomechanical and biochemical properties of tissues engineered using porcine MSCs isolated from the infrapatellar fat pad and bone marrow to those derived from CC. A porcine model was chosen as they are similar to humans in terms of their genetics, anatomy and physiology (Vacanti et al., 2005). The tripotentiality of porcine MSCs from different tissue sources was first 
assessed (chondrogenic, adipogenic and osteogenic potential). Next CC and MSCs from each source were encapsulated in agarose hydrogels and cultured in the presence of TGF- $\beta 3$. Our hypothesis was that MSCs isolated from within the synovial joint would possess a potential to generate functional cartilaginous tissues comparable to $\mathrm{CC}$ isolated from articular cartilage.

\section{Materials and methods}

\subsection{Cell isolation and expansion}

Four month old porcine MSCs were aseptically harvested from the bone marrow (BM) of the femur and from the whole infrapatellar fat pad (FP) (the outer and the inner layers of the FP were not separated, but any fibrous tissue attached to the FP was removed). Chondrocytes (CC) were harvested from the articular surface of the femoro-patellar joint. Cells from each tissue source were harvested from 2 animals and pooled. BM MSCs were isolated and expanded according to a modified method developed for human MSCs (Lennon and Caplan 2006). Muscle and facia was removed and bones were sawn close to the femoral head. BM was removed from the medullary canal and transferred to a $50 \mathrm{~mL}$ tube containing expansion medium (EM) consisting of high-glucose Dulbecco's Modified Eagle Medium (hgDMEM, GlutaMAX) containing $10 \%$ foetal bovine serum and $1 \%$ penicillin (100 U/mL)streptomycin $(100 \mu \mathrm{g} / \mathrm{mL})$ (all from GIBCO, Biosciences, Dublin, Ireland). Marrow was aspirated repeatedly to break up large aggregates prior to centrifugation at $650 \mathrm{~g}$ for $5 \mathrm{~min}$. The separated fatty layer was discarded and the cell pellet was resuspended in EM, triturated through a 16 gauge needle and filtered through a $40 \mu \mathrm{m}$ nylon cell strainer (B.D. Falcon, Unitech, Dublin, Ireland). Red blood cells were lysed using $4 \%$ acetic acid and mononuclear cells were counted using a haemocytometer. 
Cartilage slices were rinsed with phosphate buffered saline containing penicillin/streptomycin $(200 \mathrm{U} / \mathrm{ml})$ and amphotericin B $(2.5 \mu \mathrm{g} / \mathrm{ml})$. Cartilage and FP pieces were incubated with DMEM/F12 containing collagenase type II (125 U/mg) (all from Sigma-Aldrich, Dublin, Ireland) for 16-18 hours under constant rotation at $37^{\circ} \mathrm{C}$. The resulting cell suspension was then filtered through a $40 \mu \mathrm{m}$ pore-size cell sieve (Falcon Ltd, Sarstedt, Ireland) and the filtrate centrifuged and rinsed with PBS twice.

CC were seeded at a density of 50,000 cells $/ \mathrm{cm}^{2}$ in $175 \mathrm{~cm}^{2} \mathrm{~T}$ flasks and expanded to passage one (P1). Viable cells were counted using a hemacytometer and $0.4 \%$ trypan blue staining. Isolated $\mathrm{CC}$ from all joints were pooled and maintained in DMEM/F-12 (Sigma-Aldrich, Arklow, Ireland) supplemented with 10\% v/v foetal bovine serum (FBS) and 100U/ml penicillin/streptomycin (GIBCO, Biosciences, Dublin, Ireland) during the expansion phase. MSCs from the BM and FP were seeded at a density of 5,000 cells $/ \mathrm{cm}^{2}$ in $175 \mathrm{~cm}^{2} \mathrm{~T}$ flasks and expanded to passage three (P3).

\subsection{Adipogenesis and Osteogenesis}

Expanded MSCs from the BM and FP were plated in $9.5 \mathrm{~cm}^{2}$ six well plates at a density of $10^{3}$ cells $/ \mathrm{cm}^{2}$ and cultured for 7 days in complete medium (DMEM GlutaMAX supplemented with 10\% v/v foetal bovine serum (FBS) and 100U/ml penicillin/streptomycin) and changed to osteogenic or adipogenic medium for 21 days. Osteogenic medium consisted of complete medium supplemented with 100nM dexamethasone, $10 \mathrm{mM} \beta$-glycerolphosphate and $0.05 \mathrm{mM}$ ascorbic acid, while adipogenic medium consisted of complete medium supplemented with 100nM dexamethasone, $0.5 \mathrm{mM}$ isobutylmethylxanthine and $50 \mu \mathrm{M}$ indomethacin (all from 
Sigma-Aldrich, Ireland). After 21 days cells were washed twice with PBS and fixed with ethanol for ten minutes. The wells were then stained for two minutes as follows: $1 \%$ oil red solution, which stains lipid deposits, was used as a marker of adipogenesis; while $1 \%$ alizarin red solution, which stains calcium deposits, was used as a marker of osteogenesis.

\subsection{Chondrogenesis}

A pellet culture system was used to assess the chondrogenic capacity of MSCs. 500,000 cells were placed in $1.5 \mathrm{ml}$ conical microtubes and centrifuged at $650 \mathrm{G}$ for 5 minutes. The pellets were cultured in a chemically defined chondrogenic medium (CM): DMEM GlutaMAX supplemented with penicillin (100 U/ml)-streptomycin (100 $\mu \mathrm{g} / \mathrm{ml}$ ) (both GIBCO, Biosciences, Ireland), $100 \mu \mathrm{g} / \mathrm{ml}$ sodium pyruvate, 40 $\mu \mathrm{g} / \mathrm{ml} \mathrm{L}$-proline, $50 \mu \mathrm{g} / \mathrm{ml} \mathrm{L}$-ascorbic acid-2-phosphate, $4.7 \mu \mathrm{g} / \mathrm{ml}$ linoleic acid, 1.5 $\mathrm{mg} / \mathrm{ml} \mathrm{BSA}$, 1× insulin-transferrin-selenium, $100 \mathrm{nM}$ dexamethasone (all from Sigma-Aldrich, Ireland) and $10 \mathrm{ng} / \mathrm{ml}$ recombinant human transforming growth factor- $\beta 3$ (TGF- $\beta 3$; Prospec, Israel). For histological evaluation the pellets were embedded in paraffin, cut into $5 \mu \mathrm{m}$ thick sections, and stained with $1 \%$ alcian blue 8GX (Sigma-Aldrich, Ireland) in $0.1 \mathrm{M} \mathrm{HCl}$ to assess glycosaminoglycan content. Immunohistochemistry was used to detect type II collagen.

\subsection{Cell-agarose constructs}

Culture-expanded CC and MSCs were encapsulated in agarose (Type VII) at a final gel concentration of $2 \%$ and a cell density of $15 \times 10^{6}$ cells $/ \mathrm{ml}$. The agarose-cell suspension was cast in a stainless steel mould to produce cylindrical constructs $(\varnothing$ $5 \mathrm{~mm} \times 3 \mathrm{~mm}$ thickness). Agarose hydrogel constructs were maintained in the CM 
described above for 6 weeks. There were 2 samples per well with $2.5 \mathrm{ml}$ of medium per construct. Medium was changed every 2-3 days. The study was designed with 5 gels per cell source at each time point; samples were analyzed at day 0, day 21 and day 42 .

\subsection{Mechanical testing}

Constructs were mechanically tested between impermeable platens using a standard materials testing machine (Zwick Roell Z005, Herefordshire, UK) with a $5 \mathrm{~N}$ load cell, as previously described (Buckley et al., 2009). Agarose constructs were kept hydrated through immersion in a PBS bath maintained at room temperature. To assess construct functionality, an unconfined stress relaxation test was performed. Contact between the loading platen and the construct was first visually confirmed following the application of a small pre-load $(0.01 \mathrm{~N})$, and then a ramp compression to $10 \%$ strain followed by a hold period until equilibrium of the sample was achieved in a period of 30 minutes. The equilibrium Young's modulus was determined from the equilibrium force. This was followed by a $1 \mathrm{~Hz}$ cyclic test at $1 \%$ strain amplitude for 10 cycles in unconfined compression to determine the dynamic modulus. Construct dimensions were measured using a toolmaker's microscope (Mitutoyo UK Ltd., Andover, UK).

\subsection{Histology and immunohistochemistry}

Constructs were fixed in $4 \%$ paraformaldehyde overnight, rinsed in PBS, embedded in paraffin and sectioned to $8 \mu \mathrm{m}$ thickness. The histological sections were stained with $1 \%$ alcian blue $8 \mathrm{GX}$ (Sigma-Aldrich, Ireland) in $0.1 \mathrm{M} \mathrm{HCl}$ to assess glycosaminoglycan content and picrosirius red to detect collagen. Collagen type I, II and $\mathrm{X}$ contents were evaluated with a standard immunohistochemical technique as 


\subsection{Biochemical analysis}

The $5 \mathrm{~mm}$ diameter constructs were cored using a $3 \mathrm{~mm}$ biopsy punch. All samples were digested in papain $(125 \mu \mathrm{g} / \mathrm{ml})$ in $0.1 \mathrm{M}$ sodium acetate, $5 \mathrm{mM}$ cysteine $\mathrm{HCl}$, 0.05 M EDTA, pH 6.0 (all from Sigma-Aldrich, Dublin, Ireland) at $60^{\circ} \mathrm{C}$ under constant rotation for 18 hours. Aliquots of the digested samples were assayed separately for DNA, collagen and sulphated glycosaminoglycan (GAG) content. DNA content was quantified using the Quant-it Picogreen DNA assay (Invitrogen, UK). The proteoglycan content was estimated by quantifying the amount of sulphated glycosaminoglycan (GAG) in constructs using the dimethylmethylene blue dyebinding assay (Blyscan, Biocolor Ltd., Northern Ireland), with a chondroitin sulphate standard. Total collagen content was determined by measuring the hydroxyproline content, using a hydroxyproline-to-collagen ratio of 1:7.69 (Kafienah and Sims 2004; Ignat'eva et al., 2007). Matrix accumulation (total collagen and GAG) was normalised to the tissue wet weight and to DNA.

\subsection{Statistical analysis}

Mechanical and biochemical properties of engineered constructs are expressed in the form of mean \pm standard deviation (SD). Five or six samples were analysed per group at each time point; 3 or 4 samples were used for mechanical and biochemical analyses and 2 samples were used for histology. Differences in mechanical and biochemical properties with cell type and/or time-in-culture were determined by a general linear model for analysis of variance with groups as factors. Statistics were performed with 
MINITAB 15.1 (Minitab Ltd., Coventry, UK) software package. Tukey's test for multiple comparisons was used to compare conditions. Commercially available software (GraphPadPrism 4, San Diego, USA) was also used for a correlation analyses and to compare correlation slopes between conditions. A level of $\mathrm{p}<0.05$ was considered significant. Each experimental arm (CC, FP and BM) was replicated at least once using MSCs isolated from 2 different porcine donors to the original donors, with the same trends observed in replicate experiments. The results of the first replicate are presented in the manuscript. The data from the second replicate is included in the correlation analysis of mechanical properties with biochemical composition (see below).

\section{Results}

\subsection{MSC Tripotentiality}

After 21 days in culture, pellets in chondrogenic conditions became spherical and increased in size, in particular the FP pellets. Alcian blue staining for GAG was stronger for FP pellets compared to BM pellets (Fig. 1). Pellets were also stained for type II collagen; the immunoreaction revealed strong staining for FP pellets in comparison with weaker staining for BM pellets (data not shown). After 3 weeks in culture with osteogenic medium BM cells deposited calcium, as evident by staining with alizarin red. In comparison, weak staining for alizarin red was observed for the FP group (Fig. 1). All the cell sources demonstrated deposition of fat generating oil droplets that stained with oil red. MSCs cultured in control conditions did not stain with either alizarin red or oil red. 


\subsection{Agarose hydrogel culture}

Histological evaluation and immunohistochemical analysis (Fig. 2) revealed CC, FP and BM groups stained positively for sulphated proteoglycan and collagen accumulation. Immunohistochemical analysis also revealed the presence of type II collagen in CC, FP and BM constructs. Only weak staining for type I and type X collagen was observed (Fig. 2). For CC seeded hydrogels, the annular region exhibited stronger type II collagen staining compared to the core, with an opposite effect observed for the MSC groups. Matrix staining appeared more diffuse for CC and FP constructs, while a more pericellular staining was observed for BM constructs. FP constructs stained strongly for alcian blue with evidence of cell clustering and development of lacunae.

Significantly greater total GAG accumulation was observed in CC seeded hydrogels in comparison to both MSC groups, while the highest collagen accumulation was found in FP constructs (Fig. 3). Overall analysis of variance results showed that GAG, total collagen and DNA deposition for each cell seeded agarose hydrogel was dependent on time in culture $(\mathrm{p}<0.0001)$, cell type $(\mathrm{p}<0.0001)$ and region of construct (annulus or core) $(\mathrm{p}<0.0001)$. At day 42, GAG accumulation for $\mathrm{CC}$ constructs reached $1.50 \% \mathrm{w} / \mathrm{w}( \pm 0.05)$ compared to $0.95 \% \mathrm{w} / \mathrm{w}( \pm 0.04)$ for $\mathrm{FP}$ constructs and $0.43 \% \mathrm{w} / \mathrm{w}( \pm 0.03)$ for $\mathrm{BM}$ constructs. At day 42 , collagen accumulation reached $0.88 \% \mathrm{w} / \mathrm{w}( \pm 0.02)$ for $\mathrm{FP}, 0.54 \% \mathrm{w} / \mathrm{w}( \pm 0.01)$ for $\mathrm{CC}$ and $0.48 \% \mathrm{w} / \mathrm{w}( \pm 0.02)$ for BM. DNA content generally increased with time for all the groups, where a reduction in DNA content was observed between day 0 and day 42 . Normalisation of the GAG content to DNA generally revealed a similar trend as the normalisation to wet weight. 
GAG accumulation was higher in the core region of the construct for the two MSC groups, compared to greater GAG accumulation in the annular region for CC constructs (Fig. 4). By day 42, in terms of percentage of wet weight the core regions of BM and FP scaffolds showed significantly greater GAG accumulation compared to their corresponding annular region $(\mathrm{BM}$ annulus $=0.27 \pm 0.04 \% \mathrm{w} / \mathrm{w}, \mathrm{BM}$ core $=0.79$ $\pm 0.06 \% \mathrm{w} / \mathrm{w}, \mathrm{FP}$ annulus $=0.61 \pm 0.06 \% \mathrm{w} / \mathrm{w}$ and FP core $=1.48 \pm 0.11 \% \mathrm{w} / \mathrm{w})$ Similar differences were observed in core-annulus accumulation when normalised by DNA content, but with higher GAG/DNA in the core regions of CC constructs compared to their annulus (Fig. 4). FP cores contained similar amounts of GAG per DNA $(112.85 \mu \mathrm{g} / \mu \mathrm{g} \pm 8.58)$ as the core $(127.71 \mu \mathrm{g} / \mu \mathrm{g} \pm 4.45)$ and annular $(110.32$ $\mu \mathrm{g} / \mu \mathrm{g} \pm 6.16)$ region of $\mathrm{CC}$ constructs.

Total collagen accumulation in MSC constructs was greater in the core compared to the annulus $(\mathrm{BM}$ annulus $=0.43 \pm 0.01 \% \mathrm{w} / \mathrm{w}, \mathrm{BM}$ core $=0.66 \pm 0.02$ $\% \mathrm{w} / \mathrm{w}, \mathrm{FP}$ annulus $=0.56 \pm 0.02 \% \mathrm{w} / \mathrm{w}$ and $\mathrm{FP}$ core $=1.383 \pm 0.1 \% \mathrm{w} / \mathrm{w}) . \mathrm{CC}$ collagen content was lower in the core $(0.38 \pm 0.04 \% \mathrm{w} / \mathrm{w})$ in comparison with the annulus $(0.66 \pm 0.09 \% \mathrm{w} / \mathrm{w})$. When normalised by DNA, collagen values were higher in the core of the FP constructs compared to other groups.

For BM constructs, no significant differences were observed in the DNA content between annular or core regions. DNA content was higher within core regions (131.87 ng/mg w/w \pm 7.12 ) for FP constructs in comparison with the annulus (109.50 $\mathrm{ng} / \mathrm{mg} \mathrm{w} / \mathrm{w} \pm 1.17$ ). The opposite trend was observed in $\mathrm{CC}$ constructs, with DNA content of $107.68 \mathrm{ng} / \mathrm{mg} \mathrm{w} / \mathrm{w}( \pm 9.14)$ for the core region and $131.87 \mathrm{ng} / \mathrm{mg} \mathrm{w} / \mathrm{w}( \pm$ 7.12) for the annulus.

Time and cell type were significant factors in both mechanical measures $(\mathrm{p}<0.05)$. After 42 days of culture $\mathrm{CC}$ constructs exhibited higher equilibrium 
modulus (39.4kPa \pm 0.3$)$ compared to MSC constructs ( $\mathrm{p}<0.001)$ (Fig. 5). Within the MSCs groups, FP gels demonstrated comparable equilibrium modulus $(16.9 \mathrm{kPa} \pm 1.6)$ to that of $\mathrm{BM}$ constructs $(15.6 \mathrm{kPa} \pm 0.61)$. The dynamic modulus significantly increased $(\mathrm{p}<0.05)$ with time in culture for all groups. In the FP group the modulus increased from $(29.0 \mathrm{kPa} \pm 0.62)$ at day 0 to $(133.7 \mathrm{kPa} \pm 8.4)$ at week 6 , in the $\mathrm{BM}$ group from $(33.6 \mathrm{kPa} \pm 1.62)$ to $(112.6 \mathrm{kPa} \pm 13.7)$ and in the $\mathrm{CC}$ group from $(38.1 \mathrm{kPa}$ $\pm 0.19)$ to $(256.8 \mathrm{kPa} \pm 9.9)$. The dynamic modulus of FP constructs was significantly higher than BM constructs after 6 weeks of culture $(\mathrm{p}<0.05)$.

\subsection{Structure-function correlation analysis}

The equilibrium modulus and dynamic modulus at day 42 were plotted against the percentage of wet weight of total collagen and GAG content for CC, FP and BM constructs (Fig. 6). All correlations were found to be statistically significant (Table 1), except the relation between total collagen content and the equilibrium modulus in the FP group. Comparisons between groups were not statistically significant.

\section{Discussion}

In this study we evaluated the potential of porcine BM and infrapatellar FP MSCs embedded in agarose hydrogels to generate functional cartilaginous tissue, and compared the properties of these tissues to those generated using $\mathrm{CC}$ isolated from articular cartilage. Our objective was not to identify the optimal isolation, expansion and chondrogenic differentiation conditions for different MSC sources, but rather to compare composition-function relations of cartilaginous tissues generated using a number of different cell sources under near identical culture conditions. 
Understanding how the functional properties of cartilaginous tissue evolve is an essential pre-requisite to the development of any MSC-based therapy regardless of the cell source. While porcine BM and FP derived MSCs underwent robust chondrogenesis in agarose culture, construct properties were overall inferior to $\mathrm{CC}$ seeded constructs. This agrees in part with a previous study using a hyaluronan-based scaffold that demonstrated that cartilaginous constructs generated using human CC contained higher fractions of GAG compared to FP derived cells and other cell sources, and only constructs generated using CC stained positive for type II collagen (Marsano et al., 2007). Interestingly, in the present study core levels of total GAG and collagen accumulation in the FP group were comparable to that found in the $\mathrm{CC}$ group, suggesting that under the environmental conditions created in the core of these constructs, the chondrogenic capability of FP MSCs is comparable to CC. Therefore while we were unable to fully corroborate our initial hypothesis that FP derived MSCs possess a potential to generate functional cartilaginous tissues comparable to $\mathrm{CC}$, these are a source of chondro-progenitor cells worthy of further investigation for cartilage regeneration therapies.

The infrapatellar FP is composed of adipocytes and adipose connective tissue containing collagen and glycosaminoglycans, covered by a layer of synovial membrane which articulates with the trochlear cartilage of the distal femur (Mochizuki et al., 2006). MSCs from the FP are presumably derived either from the perivascular region of vessels and capillaries invading the tissue (Khan et al., 2008), and/or from the synovial layer (De Bari et al., 2001) that covers the tissue. It has recently been demonstrated that MSCs isolated from intra-articular tissues and CC share similar gene expression profiles distinct from other mesenchymal tissue-derived cells such as bone marrow and adipose derived MSCs (Segawa et al., 2009). 
Differences in gene expression profiles, possibly due to differences in their respective stem cell niches, provide one possible explanation for the apparent superior functional properties of FP constructs compared to BM constructs in this study. However, direct comparisons of different MSC sources must, for a number of reasons, be made with caution. Firstly, the initial fraction of MSCs within the different tissues has not been measured, and therefore the exact number of population doublings that have occurred in each group during the expansion phase cannot be accurately quantified. This may be important as the chondrogenic capacity of porcine BM derived MSCs is known to diminish during prolonged passaging (Vacanti et al., 2005). It should also be noted that BM derived MSCs cultured in our laboratory under similar conditions to that described here have generated cartilaginous tissues with comparable ECM content and mechanical properties to that measured here for FP derived MSCs (Thorpe et al., 2008). Variability in the chondrogenic capability of BM MSCs has been documented, compared to reports of relatively consistent chondrogenesis of synovium derived MSCs (Sakaguchi et al., 2005). Therefore, before concluding that any one source of MSCs is superior for functional cartilage tissue engineering, it will be necessary to first optimise the isolation, expansion and differentiation conditions for each cell type. For example, it has been demonstrated that the initial monolayer culture conditions used to expand adipose derived stem cells determine their subsequent chondrogenic capacity in agarose hydrogel culture (Estes et al., 2008). Future studies will investigate how variables associated with MSC expansion protocols such as plating density and growth factor supplementation (e.g. FGF-2, TGF- $\beta$ ) will influence the subsequent functional properties of engineered cartilaginous tissues, as these factors have been shown to regulate proliferation and subsequent chondrogenic differentiation of MSCs isolated from different sources (Colter et al., 2000; Erickson 
et al., 2002; Bianchi et al., 2003; Solchaga et al., 2005; Estes et al., 2006; Yanada et al., 2006; Marsano et al., 2007; Stewart et al., 2007; Khan et al., 2008; Khan et al., 2008).

GAG and collagen accumulation in MSC groups was greater in the core, while $\mathrm{CC}$ constructs had a higher concentration of extracellular matrix in the annular region. A similar inhomogeneous distribution of the extracellular matrix synthesised by MSCs embedded in agarose hydrogels was also observed in our previous studies (Thorpe et al., 2008; Buckley et al., 2009; Thorpe et al., 2010). The development of an inhomogeneous cartilaginous tissue following encapsulation of CC in agarose has also previously been reported (Kelly et al., 2006; Buckley et al., 2009; Kelly et al., 2009). This distribution seems to be specific to CC in agarose gels and may be due to spatial gradients of nutrients, oxygen and growth factors. The reason for the specific matrix distributions has not yet been elucidated, but it does suggest that $\mathrm{CC}$ and MSCs respond differently to the gradients in regulating factors present within the developing tissue.

The mechanical properties of MSC seeded hydrogels were lower than those of CC seeded hydrogels after 21 and 42 days in culture under identical conditions. It has previously been reported that immature MSCs may possess a more limited chondrogenic capacity compared to CC in an agarose hydrogel model (Mauck et al., 2006; Vinardell et al., 2009). The results of this study extend this finding to other sources of MSCs. Composition-function relations (Figure 6) revealed that even in cases where total GAG and collagen content was comparable or higher in FP hydrogels, the equilibrium modulus of the engineered tissue was higher for CC seeded constructs. This result is unexpected, as the equilibrium modulus is strongly dependant on the GAG and collagen content. Differences in the basic structure and 
properties of proteoglycans synthesised by MSCs and CC may partially explain these results, although it has been suggested that the bone marrow MSC-produce aggrecan with a phenotype more characteristic of young tissue than chondrocyte-produced aggrecan (Kopesky et al., 2010). The types of proteoglycan synthesised by engineered tissues from different cell sources, and their ability to assemble, aggregate and form a stable tissue, may also play a key role (Connelly et al., 2008; Babalola and Bonassar 2010).

The spatial composition and organization of engineered cartilage tissues will also influence the apparent mechanical properties of the construct (Kelly and Prendergast 2004). Mechanical tests such as that utilized in this study to quantify construct properties make the assumption of tissue homogeneity. The spatial distribution of GAG within CC seeded constructs is typically more homogenous than MSC groups, where the majority of GAG is accumulated within the construct core (Figure 5). Such an inhomogeneous distribution of matrix components will lower the apparent equilibrium modulus of the tissue compared to a more homogenous construct, even if the total matrix accumulation is identical. This spatial distribution of matrix would also appear to influence the correlation between the dynamic modulus of the engineered tissue and its composition. The relationship between the total GAG content and the dynamic modulus of CC and MSC seeded constructs is quite similar, despite the spatial differences in tissue composition. However the collagen content of an engineered cartilaginous construct will also have a strong bearing on the dynamic properties of a tissue. For example, comparing the relationship between the dynamic modulus and the biochemical content in CC and FP MSC constructs, its appears that greater amounts of collagen are required in FP MSC constructs to achieve comparable 
values of dynamic modulus to $\mathrm{CC}$ constructs, which again may be due in part to the greater heterogeneity of the tissues engineered using MSCs.

It has been demonstrated that bovine $\mathrm{CC}$ in agarose hydrogels produce a more mechanically functional tissue when TGF- $\beta$ is withdrawn from the media after two weeks of culture (Byers et al., 2008), while we have demonstrated that porcine FP MSCs respond more favourably to continued growth factor supplementation (Buckley et al., 2009). In this study, all cell types received continued TGF- $\beta 3$ supplementation, so it is possible that the results of this study may be underestimating the superior functional cartilage tissue forming ability of CC compared to MSCs. Clearly more optimal expansion and differentiation conditions exist for all cell types.

While not reported in this study, we have observed that porcine subcutaneous fat derived MSCs undergo poor chondrogenesis following encapsulation in agarose hydrogels, with significant cell death occurring. Other authors have also observed decreases in cell viability following encapsulation of adipose derived MSCs in agarose hydrogels (Estes et al., 2008), and poorer chondrogenesis of adipose derived MSCs in agarose hydrogels compared to BM MSCs (Kisiday et al., 2008). A number of other studies also suggest a poorer chondrogenic capacity for adipose derived MSCs compared to other sources (Winter et al., 2003; Awad et al., 2004; Huang et al., 2005; Im et al., 2005; Afizah et al., 2007; Koga et al., 2008; Peng et al., 2008; Vidal et al., 2008; Danišovič et al., 2009; Diekman et al., 2009; Hildner et al., 2009; Jakobsen et al., 2009). Future studies will investigate whether the mixed population of cells from the synovial layer and adipose tissue of FP biopsies has a positive effect on chondrogenesis, or whether they should be used in isolation for cartilage tissue engineering. 
The results of this study demonstrate that differences in the chondrogenic capacity of different MSC sources in pellet culture reported here and in previous studies translate into differences in the functional properties of cartilage engineered using these different cell populations. Given its anatomical location, a large number of MSCs can be obtained from a FP biopsy during arthroscopy for tissue engineering therapies. There have been reports stating that removing the entire FP during total knee replacement procedures can produce postoperative pain for the patient (Meneghini et al., 2007). On the other hand, removal of the FP leads to significant improvement in symptoms and function after the surgery in cases of impingement (Ogilvie-Harris and Giddens 1994). In general, there is little clinical evidence to suggest that taking biopsies of FP could be seriously detrimental to the patient. Therefore harvesting a biopsy of FP tissue has a lower degree of invasiveness compared to bone marrow aspiration, and causes minimal complications during joint arthroscopy, especially if the goal is to treat a chondral or osteochondral defect in the joint. In conclusion, functional cartilaginous tissues can be engineered using MSCs isolated from different sources. The development of these tissues is different to those generated using CCs, suggesting that MSCs and CCs respond differently to the regulatory factors present within developing cartilaginous constructs. Using the same expansion and differentiation conditions, MSCs isolated from the FP would appear to possess a potential to generate functional cartilaginous tissues at least comparable to BM MSCs, although CC still represent a standard to which all MSC-based cartilage tissue engineering strategies should be compared. 


\section{Acknowledgements}

This work was supported by the Science Foundation Ireland under the President of Ireland Young Researcher Award (Grant No: SFI/08/YI5/B1336). We would like to acknowledge the contribution of Dr. Eric Meyer to the preparation of this manuscript. 


\section{References}

Afizah, H., Yang, Z., Hui, J. H. P., et al. 2007; A comparison between the chondrogenic potential of human Bone Marrow Stem Cells (BMSCs) and Adipose-Derived Stem Cells (ADSCs) taken from the same donors. Tissue Engineering 13(4): 659-666.

Awad, H. A., Wickham, M. Q., Leddy, H. A., et al. 2004; Chondrogenic differentiation of adipose-derived adult stem cells in agarose, alginate, and gelatin scaffolds. Biomaterials 25(16): 3211-3222.

Babalola, O. M. and Bonassar, L. J. 2010; Effects of Seeding Density on Proteoglycan Assembly of Passaged Mesenchymal Stem Cells. Cellular and Molecular Bioengineering: 1-10.

Bianchi, G., Banfi, A., Mastrogiacomo, M., et al. 2003; Ex vivo enrichment of mesenchymal cell progenitors by fibroblast growth factor 2. Experimental Cell Research 287(1): 98-105.

Buckley, C. T., Thorpe, S. D. and Kelly, D. J. 2009; Engineering of large cartilaginous tissues through the use of microchanneled hydrogels and rotational culture. Tissue Engineering - Part A 15(11): 3213-3220.

Buckley, C. T., Thorpe, S. D., O'Brien, F. J., et al. 2009; The effect of concentration, thermal history and cell seeding density on the initial mechanical properties of agarose hydrogels. J Mech Behav Biomed Mater 2(5): 512-21.

Buckley, C. T., Vinardell, T., Thorpe, S. D., et al. 2009; Functional properties of cartilaginous tissues engineered from infrapatellar fat pad-derived mesenchymal stem cells. Journal of Biomechanics. 
Byers, B. A., Mauck, R. L., Chiang, I. E., et al. 2008; Transient exposure to transforming growth factor beta 3 under serum-free conditions enhances the biomechanical and biochemical maturation of tissue-engineered cartilage. Tissue Eng Part A 14(11): 1821-34.

Caplan, A. I. 1991; Mesenchymal stem cells. Journal of Orthopaedic Research 9(5): 641-650.

Colter, D. C., Class, R., DiGirolamo, C. M., et al. 2000; Rapid expansion of recycling stem cells in cultures of plastic-adherent cells from human bone marrow. Proceedings of the National Academy of Sciences of the United States of America 97(7): 3213-3218.

Connelly, J. T., Wilson, C. G. and Levenston, M. E. 2008; Characterization of proteoglycan production and processing by chondrocytes and BMSCs in tissue engineered constructs. Osteoarthritis and Cartilage 16(9): 1092-1100.

Danišovič, L., Varga, I., Polák, Š., et al. 2009; Comparisopn of in vitro chondrogenic potential of human mesenchymal stem cells derived from bone marrow and adipose tissue. General Physiology and Biophysics 28(1): 56-62.

De Bari, C., Dell'Accio, F., Tylzanowski, P., et al. 2001; Multipotent mesenchymal stem cells from adult human synovial membrane. Arthritis Rheum 44(8): $1928-42$.

Diekman, B. O., Rowland, C. R., Caplan, A. I., et al. 2009; Chondrogenesis of adult stem cells from adipose tissue and bone marrow: Induction by growth factors and cartilage derived matrix. Tissue Eng Part A.

Dragoo, J. L., Samimi, B., Zhu, M., et al. 2003; Tissue-engineered cartilage and bone using stem cells from human infrapatellar fat pads. J Bone Joint Surg $\mathrm{Br}$ 85(5): 740-7. 
English, A., Jones, E. A., Corscadden, D., et al. 2007; A comparative assessment of cartilage and joint fat pad as a potential source of cells for autologous therapy development in knee osteoarthritis. Rheumatology (Oxford) 46(11): 1676-83.

Erickson, G. R., Gimble, J. M., Franklin, D. M., et al. 2002; Chondrogenic potential of adipose tissue-derived stromal cells in vitro and in vivo. Biochemical and Biophysical Research Communications 290(2): 763-769.

Erickson, I. E., Huang, A. H., Chung, C., et al. 2009; Differential maturation and structure-function relationships in mesenchymal stem cell- and chondrocyteseeded hydrogels. Tissue Eng Part A 15(5): 1041-52.

Estes, B. T., Diekman, B. O. and Guilak, F. 2008; Monolayer cell expansion conditions affect the chondrogenic potential of adipose-derived stem cells. Biotechnology and Bioengineering 99(4): 986-995.

Estes, B. T., Wu, A. W., Storms, R. W., et al. 2006; Extended passaging, but not aldehyde dehydrogenase activity, increases the chondrogenic potential of human adipose-derived adult stem cells. Journal of Cellular Physiology 209(3): 987-995.

Fuchs, E. and Segre, J. A. 2000; Stem cells: a new lease on life. Cell 100(1): 143-55.

Hadjantonakis, A. and Papaioannou, V. 2001; The stem cells of early embryos. Differentiation 68(4-5): 159-66.

Hildner, F., Peterbauer, A., Neuß1, S., et al. 2009; Minipig Derived Mesenchymal Stem Cells from Bone Marrow and Adipose Tissue: Comparison of Adipogenic, Osteogenic and Chondrogenic Differentiation Potential. European Cells and Materials 18 Suppl. 1,: 40. 
Huang, A. H., Farrell, M. J. and Mauck, R. L. 2009; Mechanics and mechanobiology of mesenchymal stem cell-based engineered cartilage. Journal of Biomechanics.

Huang, J. I., Kazmi, N., Durbhakula, M. M., et al. 2005; Chondrogenic potential of progenitor cells derived from human bone marrow and adipose tissue: a patient-matched comparison. J Orthop Res 23(6): 1383-9.

Ignat'eva, N. Y., Danilov, N. A., Averkiev, S. V., et al. 2007; Determination of hydroxyproline in tissues and the evaluation of the collagen content of the tissues. J Anal Chem 62(1): 51-57.

Im, G. I., Shin, Y. W. and Lee, K. B. 2005; Do adipose tissue-derived mesenchymal stem cells have the same osteogenic and chondrogenic potential as bone marrow-derived cells? Osteoarthritis Cartilage 13(10): 845-53.

Jakobsen, R. B., Shahdadfar, A., Reinholt, F. P., et al. 2009; Chondrogenesis in a hyaluronic acid scaffold: comparison between chondrocytes and MSC from bone marrow and adipose tissue. Knee Surg Sports Traumatol Arthrosc.

Johnstone, B., Hering, T. M., Caplan, A. I., et al. 1998; In vitro chondrogenesis of bone marrow-derived mesenchymal progenitor cells. Experimental Cell Research 238(1): 265-272.

Kafienah, W. and Sims, T. J. 2004; Biochemical methods for the analysis of tissueengineered cartilage. Methods Mol Biol 238: 217-30.

Kelly, D. J. and Prendergast, P. J. 2004; Effect of a degraded core on the mechanical behaviour of tissue engineered cartilage constructs: A poro-elastic finite element analysis. Medical and Biological Engineering and Computing 42(1): $9-13$. 
Kelly, T. A., Ng, K. W., Ateshian, G. A., et al. 2009; Analysis of radial variations in material properties and matrix composition of chondrocyte-seeded agarose hydrogel constructs. Osteoarthritis Cartilage 17(1): 73-82.

Kelly, T. A., Ng, K. W., Wang, C. C., et al. 2006; Spatial and temporal development of chondrocyte-seeded agarose constructs in free-swelling and dynamically loaded cultures. J Biomech 39(8): 1489-97.

Khan, W. S., Adesida, A. B., Tew, S. R., et al. 2009; The epitope characterisation and the osteogenic differentiation potential of human fat pad-derived stem cells is maintained with ageing in later life. Injury 40(2): 150-7.

Khan, W. S., Tew, S. R., Adesida, A. B., et al. 2008; Human infrapatellar fat padderived stem cells express the pericyte marker 3G5 and show enhanced chondrogenesis after expansion in fibroblast growth factor-2. Arthritis Research and Therapy 10(4).

Khan, W. S., Tew, S. R., Adesida, A. B., et al. 2008; Human infrapatellar fat padderived stem cells express the pericyte marker 3G5 and show enhanced chondrogenesis after expansion in fibroblast growth factor-2. Arthritis Res Ther 10(4): R74.

Kisiday, J. D., Kopesky, P. W., Evans, C. H., et al. 2008; Evaluation of adult equine bone marrow- and adipose-derived progenitor cell chondrogenesis in hydrogel cultures. J Orthop Res 26(3): 322-31.

Koga, H., Muneta, T., Nagase, T., et al. 2008; Comparison of mesenchymal tissuesderived stem cells for in vivo chondrogenesis: suitable conditions for cell therapy of cartilage defects in rabbit. Cell Tissue Res 333(2): 207-15. 
Kopesky, P. W., Lee, H. Y., Vanderploeg, E. J., et al. 2010; Adult equine bone marrow stromal cells produce a cartilage-like ECM mechanically superior to animal-matched adult chondrocytes. Matrix Biology.

Lennon, D. P. and Caplan, A. I. 2006; Isolation of human marrow-derived mesenchymal stem cells. Exp Hematol 34(11): 1604-5.

Maniatopoulos, C., Sodek, J. and Melcher, A. H. 1988; Bone formation in vitro by stromal cells obtained from bone marrow of young adult rats. Cell and Tissue Research 254(2): 317-330.

Marsano, A., Millward-Sadler, S. J., Salter, D. M., et al. 2007; Differential cartilaginous tissue formation by human synovial membrane, fat pad, meniscus cells and articular chondrocytes. Osteoarthritis and Cartilage 15(1): 48-58.

Mauck, R. L., Byers, B. A., Yuan, X., et al. 2007; Regulation of cartilaginous ECM gene transcription by chondrocytes and MSCs in 3D culture in response to dynamic loading. Biomech Model Mechanobiol 6(1-2): 113-25.

Mauck, R. L., Yuan, X. and Tuan, R. S. 2006; Chondrogenic differentiation and functional maturation of bovine mesenchymal stem cells in long-term agarose culture. Osteoarthritis Cartilage 14(2): 179-89.

Meneghini, R. M., Pierson, J. L., Bagsby, D., et al. 2007; The effect of retropatellar fat pad excision on patellar tendon contracture and functional outcomes after total knee arthroplasty. J Arthroplasty 22(6 Suppl 2): 47-50.

Mochizuki, T., Muneta, T., Sakaguchi, Y., et al. 2006; Higher chondrogenic potential of fibrous synovium- and adipose synovium-derived cells compared with subcutaneous fat-derived cells: distinguishing properties of mesenchymal stem cells in humans. Arthritis Rheum 54(3): 843-53. 
Ogilvie-Harris, D. J. and Giddens, J. 1994; Hoffa's disease: arthroscopic resection of the infrapatellar fat pad. Arthroscopy 10(2): 184-7.

Pei, M., He, F. and Vunjak-Novakovic, G. 2008; Synovium-derived stem cell-based chondrogenesis. Differentiation 76(10): 1044-56.

Pelttari, K., Steck, E. and Richter, W. 2008; The use of mesenchymal stem cells for chondrogenesis. Injury 39 Suppl 1: S58-65.

Peng, L., Jia, Z., Yin, X., et al. 2008; Comparative analysis of mesenchymal stem cells from bone marrow, cartilage, and adipose tissue. Stem Cells and Development 17(4): 761-773.

Pittenger, M. F., Mackay, A. M., Beck, S. C., et al. 1999; Multilineage potential of adult human mesenchymal stem cells. Science 284(5411): 143-7.

Sakaguchi, Y., Sekiya, I., Yagishita, K., et al. 2005; Comparison of human stem cells derived from various mesenchymal tissues: superiority of synovium as a cell source. Arthritis Rheum 52(8): 2521-9.

Schumann, D., Kujat, R., Nerlich, M., et al. 2006; Mechanobiological conditioning of stem cells for cartilage tissue engineering. Biomed Mater Eng 16(4 Suppl): S37-52.

Segawa, Y., Muneta, T., Makino, H., et al. 2009; Mesenchymal stem cells derived from synovium, meniscus, anterior cruciate ligament, and articular chondrocytes share similar gene expression profiles. Journal of Orthopaedic Research 27(4): 435-441.

Solchaga, L. A., Penick, K., Porter, J. D., et al. 2005; FGF-2 enhances the mitotic and chondrogenic potentials of human adult bone marrow-derived mesenchymal stem cells. J Cell Physiol 203(2): 398-409. 
Stewart, A. A., Byron, C. R., Pondenis, H., et al. 2007; Effect of fibroblast growth factor-2 on equine mesenchymal stem cell monolayer expansion and chondrogenesis. Am J Vet Res 68(9): 941-5.

Thorpe, S. D., Buckley, C. T., Vinardell, T., et al. 2008; Dynamic compression can inhibit chondrogenesis of mesenchymal stem cells. Biochemical and Biophysical Research Communications 377(2): 458-462.

Thorpe, S. D., Buckley, C. T., Vinardell, T., et al. 2010; The Response of Bone Marrow-Derived Mesenchymal Stem Cells to Dynamic Compression Following TGF- $\beta 3$ Induced Chondrogenic Differentiation. Annals of Biomedical Engineering: 1-14.

Vacanti, V., Kong, E., Suzuki, G., et al. 2005; Phenotypic changes of adult porcine mesenchymal stem cells induced by prolonged passaging in culture. J Cell Physiol 205(2): 194-201.

Vidal, M. A., Robinson, S. O., Lopez, M. J., et al. 2008; Comparison of chondrogenic potential in equine mesenchymal stromal cells derived from adipose tissue and bone marrow. Veterinary Surgery 37(8): 713-724.

Vinardell, T., Thorpe, S. D., Buckley, C. T., et al. 2009; Chondrogenesis and integration of mesenchymal stem cells within an in vitro cartilage defect repair model. Annals of Biomedical Engineering 37(12): 2556-2565.

Wickham, M. Q., Erickson, G. R., Gimble, J. M., et al. 2003; Multipotent stromal cells derived from the infrapatellar fat pad of the knee. Clin Orthop Relat $\operatorname{Res}(412):$ 196-212.

Winter, A., Breit, S., Parsch, D., et al. 2003; Cartilage-like gene expression in differentiated human stem cell spheroids: A comparison of bone marrow- 
derived and adipose tissue-derived stromal cells. Arthritis and Rheumatism 48(2): 418-429.

Yanada, S., Ochi, M., Kojima, K., et al. 2006; Possibility of selection of chondrogenic progenitor cells by telomere length in FGF-2-expanded mesenchymal stromal cells. Cell Prolif 39(6): 575-84.

Zuk, P. A., Zhu, M., Ashjian, P., et al. 2002; Human adipose tissue is a source of multipotent stem cells. Molecular Biology of the Cell 13(12): 4279-4295.

Zuk, P. A., Zhu, M., Mizuno, H., et al. 2001; Multilineage cells from human adipose tissue: Implications for cell-based therapies. Tissue Engineering 7(2): 211228.

Zuk, P. A., Zhu, M., Mizuno, H., et al. 2001; Multilineage cells from human adipose tissue: implications for cell-based therapies. Tissue Eng 7(2): 211-28. 


\section{List of figures}

\section{Figure 1:}

Osteogenic potential of mesenchymal stem cells: colonies staining positive for alizarin red staining (left column). Adipogenic potential of mesenchymal stem cells: colonies staining positive for oil red staining (right column). Chondrogenic potential of mesenchymal derived stem cells: pellet staining positive for glycosaminoglycan with alcian blue (middle column).

\section{Figure 2:}

Agarose gels seeded with either chondrocytes or mesenchymal stem cells at day 42 stained for type II collagen, alcian blue (stains glycosaminoglycans) picrosirius red (stains collagen), type X collagen and type I collagen. Original magnification x 100.

\section{Figure 3:}

DNA, GAG and total collagen content in engineered tissues at day 0,21 and 42 expressed in percentages of wet weight and per $\mu \mathrm{g}$ of DNA. Data represent the mean $\pm \mathrm{SD}$ of three samples. a significant $v s$ bone marrow, $\mathbf{b} v s$ fat pad, \# $v s$ day 21 and * $v s$ day $42 \cdot \mathrm{p}<0.05$.

\section{Figure 4:}

DNA, GAG and total collagen content in engineered tissues at day 42 expressed in percentages of wet weight and per $\mu \mathrm{g}$ of DNA in construct annulus (A) and core (C). 
Data represent the mean \pm SD of three samples. a significant $v s$ bone marrow, $\mathbf{b} v s$ fat pad, \# vs day 21 and $* v s$ day $42 . \mathrm{p}<0.05$.

\section{Figure 5:}

Equilibrium and $1 \mathrm{~Hz}$ dynamic modulus at day 0, day 21 and day 42. Data represent the mean $\pm \mathrm{SD}$ of three samples. a significant $v s$ bone marrow, $\mathbf{b} v s$ fat pad, \# $v s$ day 21 and * vs day $42 . \mathrm{p}<0.05$.

\section{Figure 6:}

Correlation plots relating measured mechanical properties to biochemical constituents. Note that replicate data from separate experiments is included in this analysis.

\section{Table 1:}

Correlation of mechanical properties and biochemical content for different sources of progenitor cells and chondrocyte constructs. Correlation coefficients relating measured mechanical properties with concentration of GAG and total collagen. NS: not significant. Note that replicate data from separate experiments is included in this analysis. 


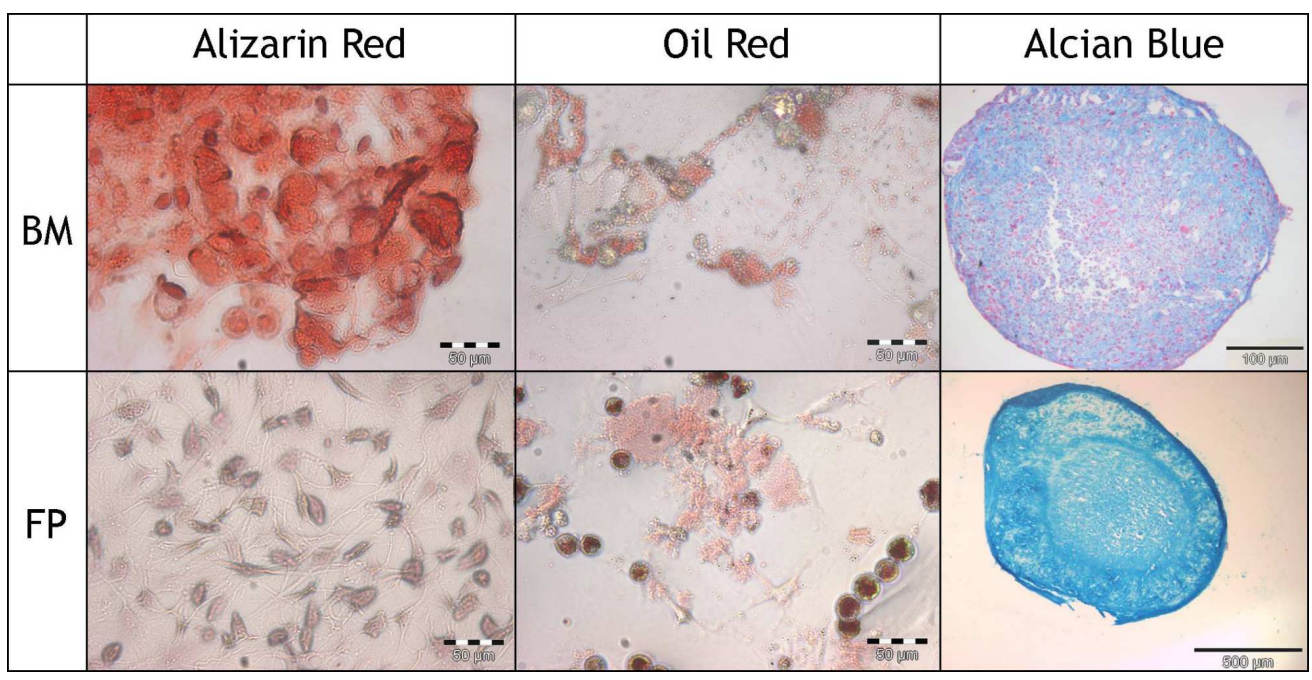

Figure 1. Osteogenic potential of mesenchymal stem cells: colonies staining positive for alizarin red staining (left column). Adipogenic potential of mesenchymal stem cells: colonies staining positive for oil red staining (right column). Chondrogenic potential of mesenchymal derived stem cells: pellet staining positive for glycosaminoglycan with alcian blue (middle column). $83 \times 42 \mathrm{~mm}(600 \times 600 \mathrm{DPI})$ 


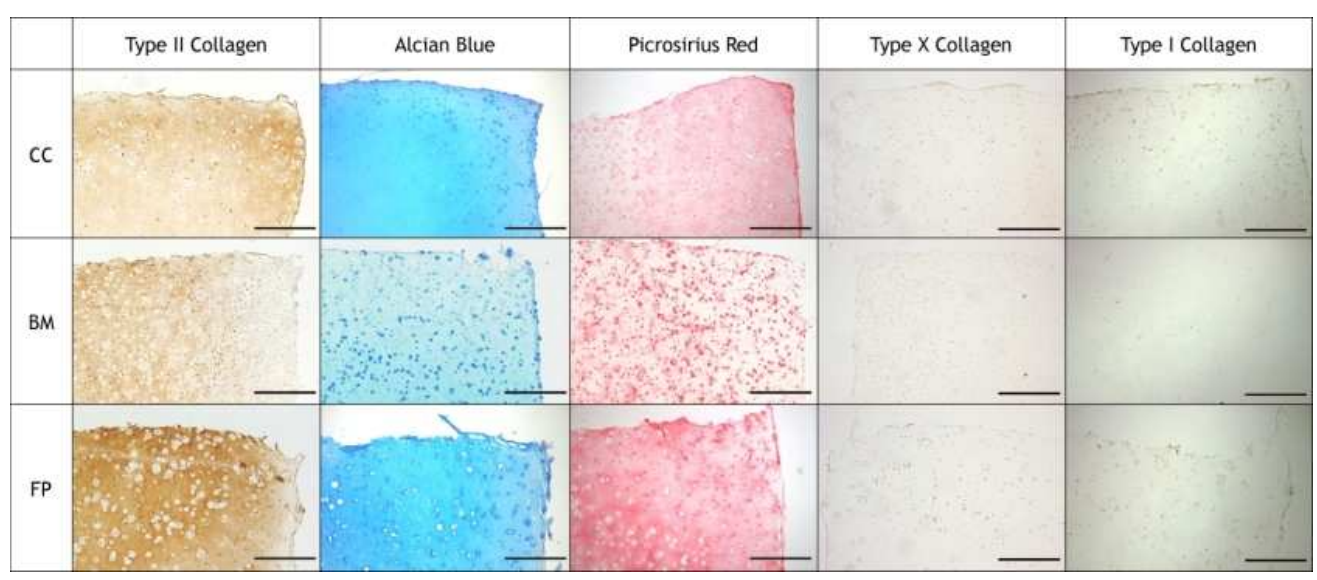

Figure 2: Agarose gels seeded with either chondrocytes or mesenchymal stem cells at day 42 stained for type II collagen, alcian blue (stains glycosaminoglycans) picrosirius red (stains collagen), type $\mathrm{X}$ collagen and type I collagen. Original magnification $\times 100$.

$71 \times 30 \mathrm{~mm}(300 \times 300 \mathrm{DPI})$ 

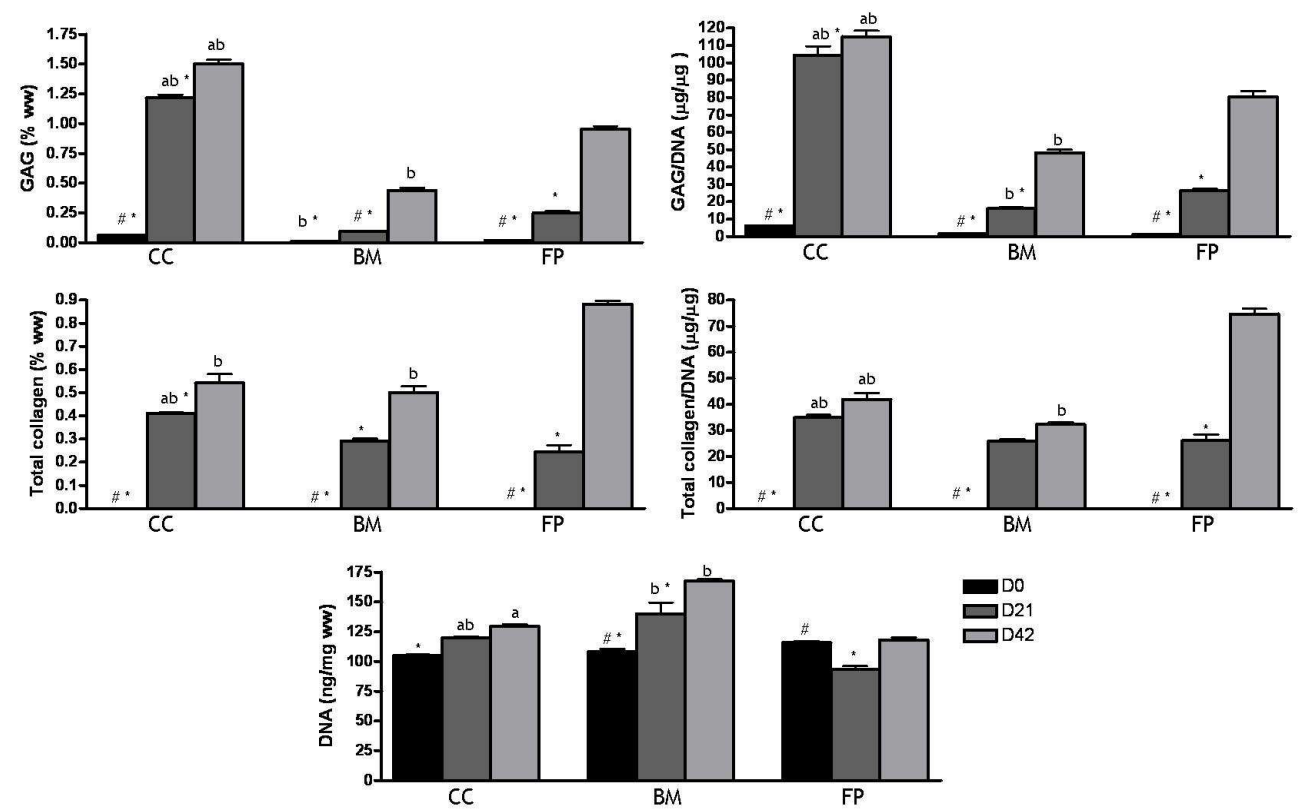

Figure 3. DNA, GAG and total collagen content in engineered tissues at day 0, 21 and 42 expressed in percentages of wet weight and per $\mu \mathrm{g}$ of DNA. Data represent the mean + SD of three samples. a significant vs bone marrow, b vs fat pad, \# vs day 21 and * vs day $42 . \mathrm{p}<0.05$. $71 \times 45 \mathrm{~mm}(600 \times 600 \mathrm{DPI})$ 

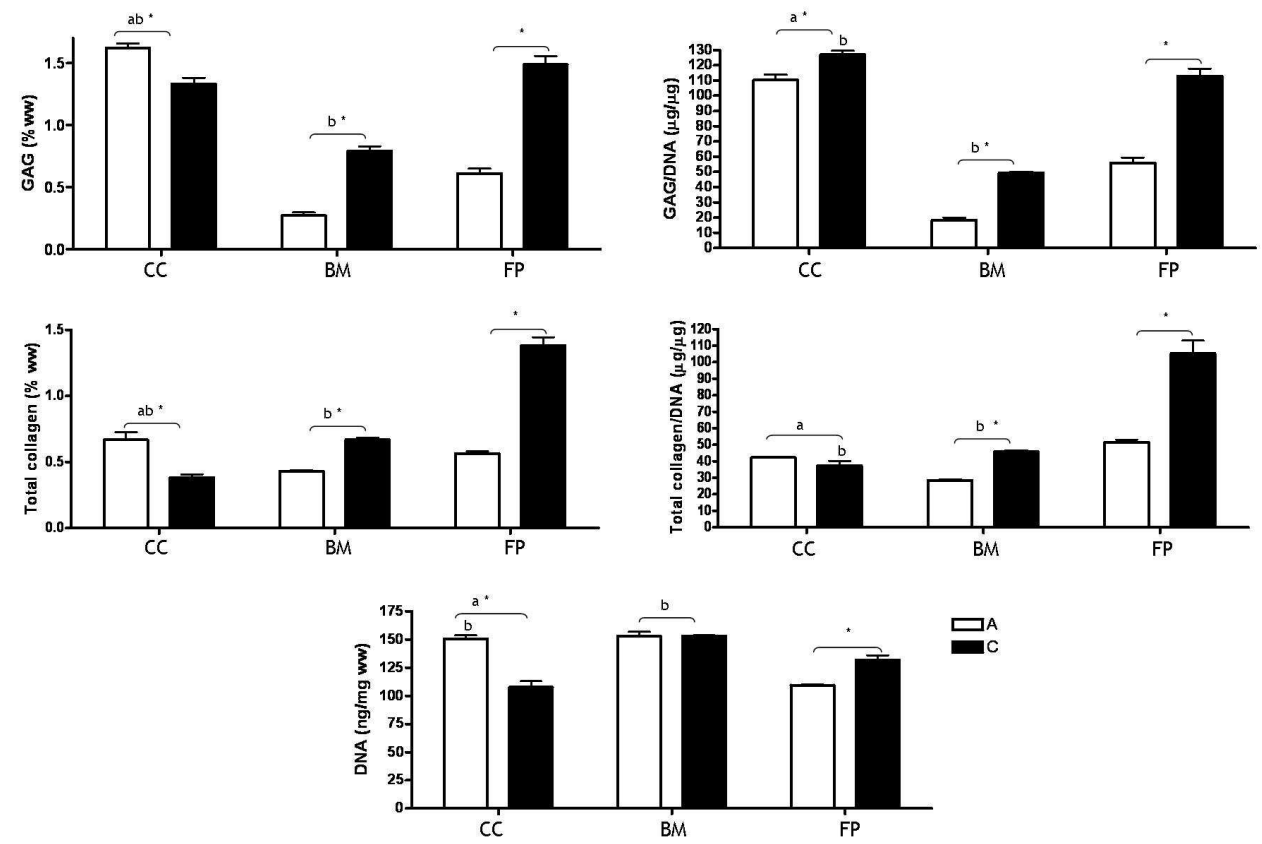

Figure 4. DNA, GAG and total collagen content in engineered tissues at day 42 expressed in percentages of wet weight and per $\mu \mathrm{g}$ of DNA in construct annulus and core. Data represent the mean + SD of three samples. a significant vs bone marrow, b vs fat pad, \# vs day 21 and * vs day $42 . \mathrm{p}<0.05$.

$78 \times 54 \mathrm{~mm}(600 \times 600$ DPI $)$ 
Figure 5. Equilibrium and $1 \mathrm{~Hz}$ dynamic modulus at day 0 , day 21 and day 42 . Data represent the mean + SD of three samples. a significant vs bone marrow, b vs fat pad, \# vs day 21 and * vs day $42 . p<0.05$.

$48 \times 33 \mathrm{~mm}(600 \times 600 \mathrm{DPI})$ 

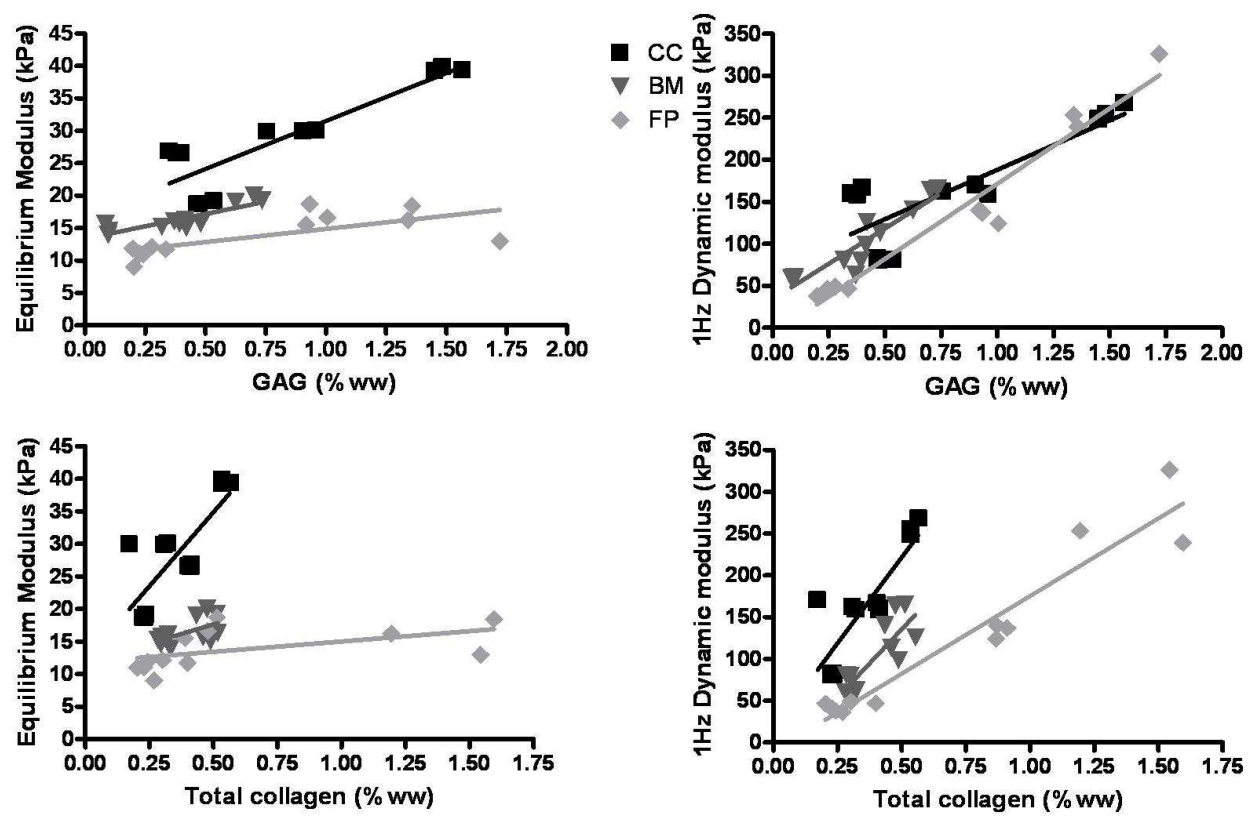

Figure 6. Correlation plots relating measured mechanical properties to biochemical constituents. Note that replicate data from separate experiments is included in this analysis. $70 \times 45 \mathrm{~mm}(600 \times 600 \mathrm{DPI})$ 
Table 1: Structure-Function Correlation

\begin{tabular}{|c|c|c|c|c|c|c|}
\hline $\begin{array}{c}\text { Cell } \\
\text { source }\end{array}$ & Comparison & Slope & $R^{2}$ & $\boldsymbol{P}$ & vs CC & vs $B M$ \\
\hline \multirow[t]{4}{*}{$\mathrm{cc}$} & Eq Modulus vs. GAG & 14.7 & 0.7797 & $P=0.0001$ & & \\
\hline & Eq Modulus vs. Total collagen & 45.5 & 0.6346 & $P<0.01$ & & \\
\hline & Dyn Modulus vs. GAG & 117.7 & 0.6939 & $P<0.001$ & & \\
\hline & Dyn Modulus vs. Total collagen & 412.2 & 0.7289 & $P<0.001$ & & \\
\hline \multirow[t]{4}{*}{ BM } & Eq Modulus vs. GAG & 7.6 & 0.7535 & $P<0.001$ & NS & \\
\hline & Eq Modulus vs. Total collagen & 11.8 & 0.3293 & $P=0.05$ & NS & \\
\hline & Dyn Modulus vs. GAG & 168.2 & 0.862 & $P<0.0001$ & NS & \\
\hline & Dyn Modulus vs. Total collagen & 327.3 & 0.7003 & $P<0.001$ & NS & \\
\hline \multirow[t]{4}{*}{ FP } & Eq Modulus vs. GAG & 4.0 & 0.4911 & $P=0.01$ & NS & NS \\
\hline & Eq Modulus vs. Total collagen & 3.1 & 0.2693 & NS & NS & NS \\
\hline & Dyn Modulus vs. GAG & 179.2 & 0.9584 & $P<0.0001$ & NS & NS \\
\hline & Dyn Modulus vs. Total collagen & 185.9 & 0.9232 & $P<0.0001$ & NS & NS \\
\hline
\end{tabular}

Table 1: Correlation of mechanical properties and biochemical content for different sources of progenitor cells and chondrocyte constructs. Correlation coefficients relating measured mechanical properties with concentration of GAG and total collagen. NS: not significant. Note that replicate data from separate experiments is included in this analysis.

$203 \times 138 \mathrm{~mm}(150 \times 150 \mathrm{DPI})$ 